\title{
A STUDY ON LONGEVITY FACTOR: THE CASE OF GOVERNMENT PENSIONER IN MALAYSIA
}

\author{
Rose Irnawaty Ibrahim* \\ Universiti Sains Islam Malaysia \\ Zailan Siri \\ University of Malaya
}

\begin{abstract}
There are many researches showing that the life expectancy for most countries is increasing. Since the life expectancy at a particular age tends to increase over time for male and female, the mortality risk tends to be smaller over time. Therefore it is expected that pensioners tend to live longer and thereby cause increase in pension liabilities to the government. Countries are looking for solutions to decrease the effect of increased longevity on pension costs. The most common changes are to equalize the retirement age for male and female and to rise the retirement age. Therefore, we studied the longevity factor for the government pensioner in Malaysia at age 55, 56, 57, 58, 59 and 60 years respectively. Since the pensions are paid for the rest of the pensioner's life in the event of his death and also to his spouse and child if any in the form of a derivative pension, the longevity factor for pensioner, spouse and child will be formulated and estimated separately. To formulate and estimate these factors, the theory of annuities and the Pension Law of Malaysia need to be studied.
\end{abstract}

Keywords: Life Expectancy; Mortality Risk; Pension Liabilities; Longevity Factor; Derivative Pension; Annuities.

\section{INTRODUCTION}

\subsection{Background}

According to the Department of Statistics, Malaysia, there has been a considerable improvement in life expectancy of the Malaysian population. Table 1 shows that life expectancy at birth of males and females has increased from 63.52 years in 1970 to 71.4 years in 2005 and from 68.21 years in 1970 to 76.1 years in year 2005 respectively, which are representing an improvement of 7.88 years and 7.89 years.

2 Corresponding Author: Dr Rose Irnawaty Ibrahim, Faculty of Science and Technology, Universiti Sains Islam Malaysia, 71800 Bandar Baru Nilai, Negeri Sembilan, Malaysia, 06-79888779, rose.irnawaty@usim.edu.my 
Table 1: Life Expectancy (years) at Birth by Sex for Malaysian Population

\begin{tabular}{ccc}
\hline Year & Male & Female \\
\hline 1970 & 63.52 & 68.21 \\
1975 & 65.40 & 70.77 \\
1980 & 66.40 & 70.50 \\
1985 & 67.71 & 72.40 \\
1990 & 68.92 & 73.52 \\
1995 & 69.42 & 74.15 \\
2000 & 70.43 & 74.93 \\
2005 & 71.40 & 76.10 \\
\hline
\end{tabular}

Source: Malaysia, Department of Statistics

The rising number of years remaining for persons of retirement age represents an additional factor to be reckoned with in examining expenditure on pension benefits. However, in the long-term future, increase in the compulsory retirement age will reduce the retirement span or in other words, there will be reduction in pension liabilities to the government.

In order to analyse a pension scheme, more important than life expectancy at birth is the life expectancy at the entrance to the scheme, say 20 to 25 years and the life expectancy at the entrance to retirement, say 55 to 60 years. Table 2 below shows the life expectancy at the entrance to the scheme, say 25 years and the life expectancy at the entrance to retirement, say 55 years for both males and females in years 1985, 1995 and 2003. This table also shows the life expectancy at the optional retirement for male (50 years) and female (45 years) in year 1985, 1995 and 2003. Besides that the table also shows the life expectancy at ages 60, 65, 70 and 75 years for both male and female in year 1985, 1995 and 2003.

Table 2 shows the average life expectancy at the age of 40 years, the permissible optional retirement for pension payment, has been gradually rising since 1985. As 55 years is the

Table 2: Life Expectancy (years) at Different Ages by Sex for Malaysian Population

\begin{tabular}{ccccccc}
\hline \multirow{2}{*}{ Age } & \multicolumn{2}{c}{1985} & \multicolumn{2}{c}{1995} & \multicolumn{2}{c}{$\mathbf{2 0 0 3}$} \\
\cline { 2 - 7 } & Male & Female & Male & Female & Male & Female \\
\hline 25 & 45.51 & 49.49 & 46.51 & 50.53 & 46.96 & 51.88 \\
40 & 31.75 & 35.27 & 32.72 & 36.12 & 33.35 & 37.38 \\
45 & 27.32 & 30.69 & 28.25 & 31.45 & 28.94 & 32.67 \\
50 & 23.08 & 26.22 & 23.93 & 26.91 & 24.59 & 28.05 \\
55 & 19.20 & 22.00 & 19.89 & 22.55 & 20.47 & 23.61 \\
60 & 15.63 & 17.98 & 16.18 & 18.42 & 16.64 & 19.38 \\
65 & 12.57 & 14.45 & 12.81 & $14, .63$ & 13.38 & 15.58 \\
70 & 9.71 & 11.14 & 9.86 & 11.20 & 10.37 & 12.08 \\
75 & 7.61 & 8.58 & 7.81 & 8.61 & 7.89 & 9.03 \\
\hline
\end{tabular}

Source: Malaysia, Department of Statistics. 
retirement age, males who retire at that age in 2003 would receive benefits for an average duration of 20.47 years and females for 23.61 years. Then, if the retirement age increases to age 60, males and females who retire at that age in 2003 would receive benefits for an average duration of 16.64 years and 19.38 years respectively. And if the retirement age increases to age 65 , males and females who retire at that age in 2003 would receive benefits for an average duration of 13.38 years and 15.58 years respectively. Therefore, we can conclude that the average period of pension payment is even longer for those who choose to retire earlier. The link between the duration of payment of pension and life expectancy at the retirement age is due to the lifetime perspective of the Government Pension Scheme. Pensions are paid for the rest of the pensioner's life in the event of his death and the pension is also paid to his spouse and child if any in the form of a derivative pensions. In addition, the longer life expectancy of the population will increase the number of recipients of retirement benefits and derivative pension since more pensioners and their survivors would be paid for a longer period of time.

There are many researches showing that the life expectancy for most countries is increasing. Since the life expectancy at a particular age tends to increase over time for male and female, the mortality risk tends to be smaller over time. Therefore it is expected that pensioners tend to live longer and thereby cause increase in pension liabilities to the government. Lindell (2003) suggested that the problem of increasing life expectancy in pension scheme can be solved by adjusting the accrued pension when granted to the latest discovered mortality rates and raising the set retirement age. Leibfritz (2003) stated that in order to reduce burden on pension financing the employee should retire at a later age as people on average are living longer which consequently will raise the public pension payments. Besides that the healthy people may wish to work longer, rather than stop working or accept low pensions. On the employer or government side, an increase in the retirement age may lead employer or government to benefit from the experience of older employees. Finally, he concluded that if retirement is delayed, these market conditions would have been improved.

Rappaport (2002) concluded that increasing longevity, in the absence of other changes, affects a fundamental balance in society, between those who work to provide goods and services and those who have retired but continue to consume those goods and services. The individual, the family, and the private and public sectors will be affected. It will also affect the future governmental programs of helping the elderly, and the poor in general. Therefore, many voices worldwide have spoken out of favour of raising retirement ages to maintain this balance as our population age. In addition, the impact of decrease in the mortality rate is common to all pension schemes around the world. To counteract this impact, Machnes (2000) suggested an increase in the contributions of the members who still are working, a raise in the retirement age or a decrease in the benefits given to pensioners.

In most countries the retirement ages in the statutory pension schemes are present. Previously changes in retirement ages were not so common. The trend was more to offer pathways to early retirement besides the standard retirement age. Since the 1990s the trend has changed. Countries are looking for solutions to decrease the effect of increased longevity on pension costs. The most common changes are to equalize the retirement age for male and female and to rise the retirement age up to 65 years old. For example, United Stated has decided to rise 
the retirement age beyond 65 years old. The retirement age for male is 65 and female is 60 in Great Britain. And this country also has decided to rise the retirement for female to 65 in year 2010. If we look in Asian country such as Japan, their retirement age is 60 years old and this country also has decided to rise their retirement to 65 in year 2013, Singapore (62 years), Thailand (60 years) and India (58 years).

The Malaysia government had extended the compulsory retirement age from 55 to 56 years old with an option to retire earlier. The extended of the compulsory retirement age had enforced by the authority on 1st October 2001. This new enforcement will offer longer period of services for the government employee whereby they will earn one more year salary payable monthly during their services. In government view of point, they will save an amount of money in the form of the pension that are not payable to the pensioner who supposedly retired on age 55 but had choose to retire at age 56. Therefore it is important to conduct a study on the longevity factor for the pensioner survives and death in Malaysia as the age of compulsory retirement increase from 55 to 60 years in phases of one year.

\section{REVIEW ON LIFE ANNUITIES}

Pension is usually a stream payment made in form of annuity to pensionable government employees and their survivors. Thus, we can say that pension is a special type of life annuities. Life annuities are regular series of payments which continue while the life assured is still alive. Usually, an annuity ends with the death of the holder but can be designed to be paid during the lives of more than one person as discussed by Neill (1977), Jordon (1967) and Hooker (1957). A number of expressions in common use are defined below:

Single Life Annuity: An annuity payable on the life of one individual and the payment ceases when the policyholder dies.

Joint Life Annuity: An annuity which depends on more than one life. For example in pension scheme, where a continuing pension is paid to a eligible dependents such as surviving spouse and other named beneficiary following the death of the pensioner.

In the study, we shall consider only two commutation functions for single life and also two commutation functions for joint lives which are defined as:
(i) $D_{x}=v^{x} l_{x}$
(ii) $N_{x}=D_{x}+D_{x+1}+D_{x+2}+\cdots$
(iii) $D_{x y}=v^{\frac{1}{2}(x+y)} l_{x y}$
(iv) $N_{x y}=D_{x y}+D_{x+1: \mathrm{y}+1}+D_{x+2: \mathrm{y}+2}+\cdots$

In practice, annuities may be paid more frequently such as quarterly, semi-annually, or annually. However, pensions are often paid monthly. For example under Malaysian Government Pension Scheme, the payments are usually made on a monthly basis and it will be payable at the end of the month. If the payment is payable at the end of each year for a life aged $x$ of the participant 
and cease upon the death of the participant, the present value of 1 payable at the end of each year $^{1}$ is given by

$$
a_{x}=\frac{N_{x+1}}{D_{x}}
$$

And the present value of 1 payable $m$ times at the end of each year to a life aged $x$ is denoted by $a_{x}^{(m)}$, and consists of payments, each of $1 / \mathrm{m}$, at age $x+1 / m, x+2 / m, x+3 / m$. Therefore, the present value may be written by

$$
a_{x}^{(m)} \underset{\&}{\mathrm{~B}} a_{x}+\frac{m-1}{2 m}
$$

The present value of 1 payable at the end of each year and continuous which ceases on the later of the death of a life aged $x$ for a fixed period of time $\mathrm{n}$ is denoted by $a_{x: n}$. It is can be derived as follows:

$$
\begin{aligned}
a_{x: n} & =a_{x}-{ }_{n} / a_{x}=a_{x}-\left(v^{n} \mathrm{X}_{n} p_{x} \times a_{x+n}\right) \\
& =\frac{N_{x+1}}{D_{x}}-\left(\frac{D_{x+n}}{D_{x}} \times \frac{N_{x+n+1}}{D_{x+n}}\right)=\frac{N_{x+1}-N_{x+n+1}}{D_{x+n}}
\end{aligned}
$$

Also the present value of 1 payable at the end of each year and continuous which ceases on the later of the death of a life aged $x$ for a fixed period of time $\mathrm{n}$ and payable $\mathrm{m}$ times a year is denoted by $a_{x: n}$. It is can be derived as follows:

$$
\begin{aligned}
a_{x: n}^{(m)} & =a_{x}^{(m)}-{ }_{n} / a_{x}^{(m)}=a_{x}^{(m)}-v^{n} \mathrm{x}_{n} p_{x} \mathrm{x} a_{x+n}^{(m)} \\
& \stackrel{\mathrm{B}}{\&}\left(a_{x}+\frac{m-1}{2 m}\right)-\frac{D_{x+n}}{D_{x}}\left(a_{x+n}+\frac{m-1}{2 m}\right) \\
& \mathrm{B}\left(\frac{N_{x+1}}{D_{x}}+\frac{m-1}{2 m}\right)-\frac{D_{x+n}}{D_{x}}\left(\frac{N_{x+n+1}}{D_{x+n}}+\frac{m-1}{2 m}\right) \\
& \stackrel{\mathrm{B}}{\&}\left(\frac{N_{x+1}-N_{x+n+1}}{D_{x}}\right)+\frac{m-1}{2 m}\left(1-\frac{D_{x+n}}{D_{x}}\right)
\end{aligned}
$$

1 For detail refer to Neill (1977), Jordon (1967) and Hooker (1957). 
The joint life annuities also important in the study because we are interested on the pension factor for the spouse and the child. Joint annuity payable to a life aged $y, m$ times a year and commences at the end of each year in which a life aged $x$ dies is denoted by $a_{x / y}^{(m)}$. It is can be derived as follows:

$$
a_{x / y}^{(m)}=a_{y}^{(m)}-a_{x y}^{(m)}
$$

Then, by using equation (2), $a_{x / y}^{(m)}$ will becomes

$$
\begin{aligned}
a_{x y y}^{(m)} & =a_{y}^{(m)}-a_{x y}^{(m)} \\
& \underset{\mathrm{B}}{\mathrm{B}}\left(\frac{N_{y+1}}{D_{y}}+\frac{m-1}{2 m}\right)-\left(\frac{N_{x+1: y+1}}{D_{x y}}+\frac{m-1}{2 m}\right)
\end{aligned}
$$

Also the joint annuity with period certain payable to a life aged $y, m$ times a year after a life aged $x$ die with no payments to be made after $n$ years from the present time is denoted by $a_{x / y: n}^{(m)}$. It is can be derived as follows:

$$
a_{x / y: n}^{(m)}=a_{y: n}^{(m)}-a_{x y: n}^{(m)}
$$

By using equation (4), $a_{x / y: \bar{n}}^{(m)}$ will becomes

$$
\begin{aligned}
a_{x \mid y: n}^{(m)}=a_{y: n}^{(m)}-a_{x y: n}^{(m)} \stackrel{\mathrm{B}}{\&} & {\left[\left(\frac{N_{y+1}-N_{y+n+1}}{D_{y}}\right)+\frac{m-1}{2 m}\left(1-\frac{D_{y+n}}{D_{y}}\right)\right] } \\
- & {\left[\left(\frac{N_{x+1: \mathrm{y}+1}-N_{x+n+1: y+n+1}}{D_{x y}}\right)+\frac{m-1}{2 m}\left(1-\frac{D_{x+n: y+n}}{D_{x y}}\right)\right] }
\end{aligned}
$$

\section{ANALYSIS OF DATA COLLECTION}

Since the data on members of parliament, politic secretaries, judges, members of commission and members of military are confidential, the study only focuses on government employees except the members of parliament, politic secretaries, judges, members of commission and members of military. The past raw data on pensioners and their survivors, and also pensioners who retired at age 55 and died during retirement and their survivors (spouse and children) are collected from the Pension Department, Public Service Department (PSD) Malaysia. The referred set was from year 1991 to 2000 and the information required are: date of birth, date of 
entry to scheme, date of retirement, date of death, gender, final monthly basic salary and also information on their dependants such as date of birth, status and gender. The most common adjustment is to exclude persons of unknown date of birth, date of entry to scheme, date of retirement, date of death, sex and final monthly basic salary. The data were reviewed, analysed, and validated year by year.

\section{METHODOLOGY}

Expected present value of an annuity is the single amount of dollars today that is equivalent to all future payments under the terms of the annuity. In the context of the life office, expected present value is the amount of money required to pay the benefit with the assumption that the money invested earn an effective rate of interest of $i$ per annum. The expected present value is not know precisely, however it can be modelled as a random variable taking into consideration both interest and mortality factors.

Pensions are paid for the rest of the pensioner's life in the event of his death and the pension is also paid to his spouse and child if any in the form of a derivative pensions. Therefore to estimate the longevity factor for the pensioner survives and death, the longevity factor for pensioner, spouse and child need to be estimated separately using the theory of annuities. Before we can estimate these factors, we need to formulate the formula for longevity factor for pensioner, spouse and child separately. Hence, the formulations for the longevity factor are divided into three parts, which are formulating

(i) Longevity Factor for Pensioner

(ii) Longevity Factor for Spouse

(iii) Longevity Factor for Child

However, we will discuss each one in turn:

\section{(i) Longevity Factor for Pensioner, $L_{i}^{x}(p)$ :}

Firstly, the longevity factor for the pensioner will be formulated. From the theory of annuities, the longevity factor for pensioner who choose to retire at age $\mathrm{x}$ can be written as

$$
L_{i}^{x}(p)=a_{x}^{(12)} \underset{\&}{\mathrm{~B}} a_{x}+\frac{11}{24} \stackrel{\mathrm{B}}{\&} \frac{N_{x+1}}{D_{x}}+\frac{11}{24}
$$

Where; $L_{i}^{x}(p)=$ The longevity factor for a particular pensioner $i$ who choose to retire at age $\mathrm{x}$ and in the study $x=55,56,57,58,59,60$.

\section{(ii) Longevity Factor for Spouse, $L_{i}^{x}(s)$ :}

In order to formulate the longevity factor for spouse, the Pensions Laws of Malaysia need to be studied. According to the Pensions Laws of Malaysia (2001), if the pensionable government employee dies in service or in retirement within the period of 12.5 years, the spouse will 
receive 100 percent monthly pension and after that the amount reduces to 70 percent. But if the pensionable government employee dies after the period of 12.5 years, the spouse will receive 70 percent monthly pension. Therefore, the longevity factor for the spouse can be written as

$$
\begin{aligned}
L_{i}^{x}(s)= & 100 \% a_{x y y: \overline{12.5}}^{(12)}+70 \%\left[\frac{l_{x}-l_{x+12.5}}{l_{x}} * \frac{l_{y+12.5}}{l_{y}}\right\rceil v^{12.5} a_{y+12.5}^{(12)}+70 \% \\
& {\left[\frac{l_{x+12.5}}{l_{x}} * \frac{l_{y+12.5}}{l_{y}}\right\rceil v^{12.5} a_{x+12.5 / y+12.5}^{(12)} }
\end{aligned}
$$

Where; $L_{i}^{x}(s)=$ The longevity factor for a spouse of a particular pensioner $i$ who choose to retire at age $\mathrm{x} ; x=$ Retirement age of pensioner; and $\mathrm{y}=$ Age of spouse.

However, equation (10) can be simplified by using the theories of annuities in previous section.

\section{(iii) Longevity Factor for Child, $L_{i}^{x}(c)$ :}

To formulate the longevity factor for child, the Pensions Laws of Malaysia need to be studied as well. As mentioned earlier, if the pensionable government employee dies in service or in retirement within the period of 12.5 years, the survivors will receive 100 percent monthly pension and after that the amount reduces to 70 percent. But if the pensionable government employee dies after the period of 12.5 years, the survivors will receive 70 percent monthly pension. Also according to the Pensions Laws of Malaysia, the children are eligible for the derivative pension until age 21 years or till $1^{\text {st }}$ Degree. However, in the study we assume that the children are eligible for the derivative pension until age 21 years only. Because of these two constraints, the longevity factor for the child is divided into two, depending on the age of the child. The formula below is used in formulating the longevity factor for the child age one up to nine.

$$
\begin{aligned}
L_{i}^{x}(c)= & 100 \% a_{x / z: \overline{12.5}}^{(12)}+70 \%\left(\frac{l_{x}-l_{x+12.5}}{l_{x}} * \frac{l_{z+12.5}}{l_{z}}\right) v^{12.5} a_{z+12.5: n}^{(12)}+70 \% \\
& \left(\frac{l_{x+12.5}}{l_{x}} * \frac{l_{z+12.5}}{l_{z}}\right) v^{12.5} a_{x+12.5 / z+12.5: n}^{(12)}
\end{aligned}
$$

Where; $L_{i}^{x}(c)=$ The longevity factor for a child of a particular pensioner $i$ who choose to retire at age $x ; x=$ The retirement age of pensioner; and $\mathrm{z}=$ Age of child.

The value of " $n$ " will depend on the age of the child.

\begin{tabular}{lccccccccc} 
Child age, $\boldsymbol{z}$ & 1 & 2 & 3 & 4 & 5 & 6 & 7 & 8 & 9 \\
Value of $\boldsymbol{n}$ & 8.5 & 7.5 & 6.5 & 5.5 & 4.5 & 3.5 & 2.5 & 1.5 & 0.5 \\
\hline
\end{tabular}


The value of " $n$ " is decreasing as the age of child increasing. The value of " $n$ " is equal to 0.5 , and since the value of ' $n$ ' is fractional, we need to estimates. For $z=1, n=8.5$, we estimate the value of ' $n$ ' by dividing by two where $n=8$ and $n=9$. We denote $n_{1}=8$ and $n_{2}=9$. However, equation (11) can be simplified by using the theories of annuities in previous section.

And when the child attained age 10 years to age 21 years, formula of longevity factor for child will become as follows:

$$
L_{i}^{x}(c)=a_{x / z: n}^{(12)}
$$

The value of " $n$ " will depend on the age of the child.

\begin{tabular}{ccccccccccccc}
\hline Child age, $\boldsymbol{z}$ & 10 & 11 & 12 & 13 & 14 & 15 & 16 & 17 & 18 & 19 & 20 & 21 \\
Value of $\boldsymbol{n}$ & 12 & 11 & 10 & 9 & 8 & 7 & 6 & 5 & 4 & 3 & 2 & 1 \\
\hline
\end{tabular}

Also to make the equation (12) easier, we simplify it in term of commutation function by using equations (5) and (6) in previous section.

Then, to estimate the longevity factor for pensioner survives, we built four types of family models which are as follows:

The pensioner is single (p).

The pensioner has the eligible spouse only (ps).

The pensioner has the eligible children only (pc).

The pensioner has the eligible spouse and children (psc).

Let;

$L_{i}^{x}(p s)=$ The longevity factor for a particular single pensioner $i$ who choose to retire at age $x$ and has the eligible spouse only;

$L_{i}^{x}(p c)=$ The longevity factor for a spouse of a particular single pensioner $i$ who choose to retire at age $x$ and has the eligible children only;

$L_{i}^{x}(p s c)=$ The longevity factor for a child of a particular single pensioner $i$ who choose to retire at age $x$ and has the eligible spouse and children; and

$P_{p}, P_{p s}, P_{p c}$, and $P_{p s c}=$ The probability for each type of family model mentioned above. 
Thus the longevity factor for pensioner survives can be written as:

$$
L_{i}^{x}=p_{p} \times L_{i}^{x}(p)+p_{p s} \times L_{i}^{x}(p s)+p_{p c} \times L_{i}^{x}(p c)+p_{p s c} \times L_{i}^{x}(p s c)
$$

Where; $L_{i}^{x}(p s)=L_{i}^{x}(p)+L_{i}^{x}(s) ; L_{i}^{x}(p c)=L_{i}^{x}(p)+L_{i}^{x}(c)$; and

$$
L_{i}^{x}(p s c)=L_{i}^{x}(p)+L_{i}^{x}(s)+L_{i}^{x}(c) \text {. }
$$

And for the pensioner death, we built three types of family models which are as follows:

The pensioner has the eligible spouse only (s).

The pensioner has the eligible children only (c).

The pensioner has the eligible spouse and children (sc).

Thus the longevity factor for pensioner death can be written as:

$$
L_{i}^{d(x)}=p_{s} \times L_{i}^{x}(s)+p_{c} \times L_{i}^{x}(c)+p_{s c} \times L_{i}^{x}(s c)
$$

Where; $L_{i}^{x}(s c)=L_{i}^{x}(s)+L_{i}^{x}(c)$; and $p_{s}, p_{c}$, and $p_{s c}$ are the probability for each type of family model mentioned above.

However, all the estimated results of longevity factor are presented and discussed in the next section.

\section{RESULTS AND DISCUSSION}

As mentioned before, it is important to note that the longevity factor is determined by considering both interest rate and mortality rate $^{2}$. Firstly, the estimated longevity factor for pensioner, spouse and child will be discussed separately. After that the longevity factor for the pensioner survives and death in Malaysia as the age of compulsory retirement increase from 55 to 60 years in phases of one year will be discussed. The estimated results for longevity factor for both males and females are presented and discussed below.

\subsection{Estimated Longevity Factor for Pensioner, $L_{i}^{x}(p)$ :}

As discussed before, the longevity factor for the pensioner can be defined as expected present value of annuities due of 1 payable 12 times a year to a life age $x$. Result of summary statistics of longevity factor obtained is given in table below.

2 Use ${ }_{n} q_{x}$ for Malaysian population. Since we only have an abridged life table for Malaysian population, we should expand it to a complete life table using the Heligman-Pollard model (Refer to Ibrahim, R.I. (2008) and Ibrahim, R. I., and Siri, Z. (2011)). 
Table 3: Summary statistics of longevity factor at a reference rate of interest 3\%, 4\% and 5\% for male and female aged 55, 56, 57, 58, 59 and 60

\begin{tabular}{cccccccccc}
\hline \multirow{2}{*}{ Age (x) } & \multicolumn{3}{c}{$\mathbf{i}=\mathbf{3} \%$} & \multicolumn{3}{c}{$\mathbf{i}=\mathbf{4} \%$} & \multicolumn{3}{c}{$\mathbf{i}=\mathbf{5 \%}$} \\
\cline { 2 - 10 } & (Male) & (Female) & (Diff) & (Male) & (Female) & (Diff) & (Male) & (Female) & (Diff) \\
\hline 55 & 14.65360 & 15.90544 & 1.25185 & 13.26245 & 14.31196 & 1.04951 & 12.08264 & 12.96941 & 0.88677 \\
56 & 14.25319 & 15.48356 & 1.23037 & 12.93285 & 13.96997 & 1.03712 & 11.80889 & 12.68967 & 0.88078 \\
57 & 13.85163 & 15.05807 & 1.20644 & 12.60038 & 13.62281 & 1.02243 & 11.53125 & 12.40394 & 0.87269 \\
58 & 13.44937 & 14.62944 & 1.18007 & 12.26542 & 13.27082 & 1.00540 & 11.25004 & 12.11247 & 0.86243 \\
59 & 13.04689 & 14.19819 & 1.15130 & 11.92838 & 12.91443 & 0.98605 & 10.96558 & 11.81558 & 0.85000 \\
60 & 12.64468 & 13.76485 & 1.12017 & 11.58971 & 12.55406 & 0.96435 & 10.67825 & 11.51360 & 0.83535 \\
\hline
\end{tabular}

As we can seen in Table 3, the longevity factor for male and female is decreasing as the interest rate increases at age 55,56,57,58,59 and 60. Moreover we found that the longevity factor for male and female is decreasing as age increases at interest rate 3 percent, 4 percent and 5 percent. Actually the longevity factor depends so much on the mortality rate and interest rate assumptions. If the mortality and interest rates are smaller than the longevity factor will be greater. We also found that the longevity factor for same retirement age will be decreased when the interest rate increasing. For example (refer to Table 3), if we refer to age 58 years the longevity factor for male with interest rate $3 \%$ is 13.44937 . Then, the longevity factor decreased to 12.26542 if we increase the interest rate to $4 \%$. And, if we increase the interest rate to $5 \%$, the longevity factor for male will be decreased to 11.25004 . It also happens for females. In addition, we can see clearly that for the same interest rate and retirement age, the longevity factor for females is always greater than males. This is because the mortality rates for females are smaller than males. Therefore, we can conclude that the longevity factor will increase when the mortality rate and interest rate decreases. Also we found that the difference in longevity factor between male and female is decreasing as the age increases.

\subsection{Estimated Longevity Factor for the Spouse, $L_{i}^{x}(s)$ :}

As mentioned before, the longevity factor for spouse can be estimated by:

$$
\begin{aligned}
L_{i}^{x}(s)= & 100 \% a_{x / y: \frac{12.5}{(12)}}+70 \%\left[\frac{l_{x}-l_{x+12.5}}{l_{x}} * \frac{l_{y+12.5}}{l_{y}}\right\rceil v^{12.5} a_{y+12.5}^{(12)}+70 \% \\
& {\left[\frac{l_{x+12.5}}{l_{x}} * \frac{l_{y+12.5}}{l_{y}}\right\rceil v^{12.5} a_{x+12.5 / y+12.5}^{(12)} }
\end{aligned}
$$

Where $x$ is age of pensioner and $\mathrm{y}$ is age of spouse.

From the analysis of past data in year 1991 to 2000 we found that the average age gap between the husband and wife is six years. However, from the report on 1984/85 Malaysian Population and Family Survey, we found that the husband was 5 or more years older. Therefore, in the 
study we assume that the age gap between the husband and wife is six years. Thus, the range age of widow or widower in the study is from 49 to 54 years. Also we assume that the interest rate of 3 percent will be used in the study. The estimated longevity factor for the widow or widower for range age 49 to 54 years with interest rate of $3 \%$ are displayed and discussed below.

Table 4: Summary statistics of the estimated longevity factor at a reference rate of interest $3 \%$ for widow and widower aged $49,50,51,52,53$ and 54

\begin{tabular}{cccc}
\hline Age of pensioner, $x$ & Age of Spouse, $y$ & $L_{i}^{x}$ (spouse -widow) & $L_{i}^{x}$ (spouse-widower) \\
\hline 55 & 49 & 3.92211 & 2.71480 \\
56 & 50 & 3.95871 & 2.75795 \\
57 & 51 & 3.99237 & 2.80008 \\
58 & 52 & 4.02290 & 2.84108 \\
59 & 53 & 4.05010 & 2.88078 \\
60 & 54 & 4.07377 & 2.91903 \\
\hline
\end{tabular}

According to Table 4, we found that when retirement age of government employee is increased, the estimated longevity factor will increase for both widow and widower. Also the estimated longevity factor for widow is greater than widower. This is because the mortality rate for female (widow) is smaller than male (widower).

\subsection{Estimated Longevity Factor for the Child, $L_{i}^{x}(c)$ :}

Also in the study, we assume the interest rate of 3 percent will be used to estimate the longevity factor for child. From the analysis of past data in year 1991 to 2000, we found that the average age of child without spouse is 12 years old and child with spouse is 13 years old. Thus in the study, we use formula of longevity factor for child age 10 years to age 21 years as follows:

$$
L_{i}^{x}(c)=a_{x_{k} / z: n}^{(12)}
$$

Where $x$ is age of pensioner and $\mathrm{z}$ is age of child.

Also from the analysis of past data in year 1991 to 2000, we found that the ratio between male and female child without spouse is $0.45: 0.55$ and the ratio between male and female child with spouse is $0.47: 0.53$. Thus in the study, we used that ratios as our assumption to estimate the longevity factor for child. The estimated longevity factor for child without spouse and with spouse for both male pensioner and female pensioner are displayed and discussed below. 
Table 5: Summary of estimated longevity factor for child without spouse and with spouse for both male and female pensioner.

\begin{tabular}{ccccc}
\hline & \multicolumn{2}{c}{ Male pensioner } & \multicolumn{2}{c}{ Female pensioner } \\
\hline $\begin{array}{c}\text { Age of } \\
\text { pensioner, } \boldsymbol{x}\end{array}$ & $L_{i}^{x}(c$-w/o spouse $)$ & $L_{i}^{x}(c$-withspouse $)$ & $L_{i}^{x}(c-$ w/o spouse $)$ & $L_{i}^{x}(c$-withspouse $)$ \\
\hline 55 & 6.75749 & 6.34357 & 6.95412 & 6.50509 \\
56 & 6.30449 & 5.84567 & 6.97655 & 6.43753 \\
57 & 5.81206 & 5.30547 & 6.44113 & 6.12584 \\
58 & 5.27744 & 4.71984 & 5.85623 & 5.51112 \\
59 & 4.69737 & 4.08512 & 5.2177 & 4.84063 \\
60 & 4.06808 & 3.39702 & 4.52066 & 4.10926 \\
\hline
\end{tabular}

The tables above shows that as the retirement age of male and female pensioner increase, the estimated longevity factor for child without spouse and with spouse slightly decreases. Also we found that the estimated longevity factor for child without spouse and with spouse for female pensioner is greater compared to male pensioner. Again this is because the mortality rate for female is smaller than male.

\subsection{Estimated Longevity Factor for Pensioner Survives, $L_{i}^{x}$ :}

From the observations and analysis of data collections, we found that 3 percent falls in Family Model I, 94.1 percent falls in Family Model II, 1.79 percent falls in Family Model III and only 1.11 percent falls in Family Model IV. Therefore, in the study we used these probabilities as our assumptions to estimate the longevity factor for pensioner survives. Thus, the longevity factor for pensioner survives becomes

$$
L_{i}^{x}=0.03 \times L_{i}^{x}(p)+0.941 \times L_{i}^{x}(p s)+0.0179 \times L_{i}^{x}(p c)+0.0111 \times L_{i}^{x}(p s c)
$$

Table 6: Summary of estimated longevity factor for both male and female pensioner survives

\begin{tabular}{crr}
\hline Age of male pensioner & $L_{i}^{x}$ - Male & $L_{i}^{x}$ - Female \\
\hline 55 & 18.57672 & 18.68437 \\
56 & 18.19761 & 18.30327 \\
57 & 17.81338 & 17.90492 \\
58 & 17.42421 & 17.49813 \\
59 & 17.03030 & 17.08592 \\
60 & 16.63183 & 16.66851
\end{tabular}


From Table 6, we can see that as the retirement age of male and female pensioner increases, the estimated longevity factors for both male and female pensioner survive slightly decreased. Also we found that the estimated longevity factor for female pensioner survives are greater compared to male pensioner survives. This is because the mortality rate for female pensioner is lower than male pensioner.

\subsection{Estimated longevity Factor for the Pensioner Death, $L_{i}^{d(x)}$ :}

And from the observations and analysis of data collections, we found that 96 percent falls in Family Model I, 3 percent falls in Family Model II and 1 percent falls in Family Model III. Therefore, in the study we used these probabilities as our assumptions to estimate the longevity factor for pensioner death. Thus, the longevity factor for the pensioner death becomes

$$
L_{i}^{d(x)}=0.96 \times L_{i}^{x}(s)+0.03 \times L_{i}^{x}(c)+0.01 \times L_{i}^{x}(s c)
$$

Table 7: Summary of estimated longevity factor for both male and female pensioner dies

\begin{tabular}{ccc}
\hline Age of male pensioner, $\boldsymbol{x}$ & $L_{i}^{d(x)}$ - Male & $L_{i}^{d(x)}$ - Female \\
\hline 55 & 4.03139 & 2.87988 \\
56 & 4.04795 & 2.92130 \\
57 & 4.06009 & 2.94257 \\
58 & 4.06751 & 2.95823 \\
59 & 4.06987 & 2.97049 \\
60 & 4.06683 & 2.97898 \\
\hline
\end{tabular}

The tables above show that as the retirement age of male and female pensioner dies increases, the estimated longevity factor for both male and female pensioner dies slightly increased. Also we found that the estimated longevity factor for male pensioner dies is greater compared to female pensioner dies. This is because the longevity factor for spouse of male pensioner dies (widow) is greater than longevity factor for spouse of female pensioner dies (widower). Beside that this because of mortality rate for females is lower than males.

However, in view of longevity factor, we can say that there is RM1 of monthly pension, where the government needs the estimated total amount of longevity factor for pensioner survives and death.

\section{CONCLUSION}

Hence from the estimated results, we concluded that the compulsory retirement age should be increased in the future in order to decrease the effect of increased longevity on pension costs. Thus, the pension liabilities to the government will be reduced and the government also in the other hand can save a huge amount of money. Therefore it is important for government 
to estimate and set up the fund in order to solve the financial burden in the future time as the number of pensioner entering the pension scheme is increasing every year.

As an indicative study, however, this study indicates that the current government pension scheme in Malaysia needs to be reformed immediately to reduce the pension liabilities to the government as the life expectancy of Malaysian population increased year by year. Or we can say that the Malaysia Government needs to increase the compulsory retirement age to solve the longevity problems and also to reduce the pension liabilities to the government.

\section{ACKNOWLEDGMENTS}

Authors would like to thanks to Universiti Sains Islam Malaysia and Ministry of Higher Education for their financial support.

\section{REFERENCES}

Hooker, P. F. (1957). Life and Other Contingencies. London: The Syndics of the Cambridge University Press.

Ibrahim, R. I. (2008). Expanding an Abridged Life Table using the Heligmann-Pollard Model. Matematika, 24(I), 1-10.

Ibrahim, R. I., \& Siri, Z. (2011). Methods of Expanding an Abridged Life Tables: Comparison between Two Methods. Sains Malaysiana, 40(12), 1449-1453.

Jordon, C. W. (1967). Life Contingencies. Chicago: Society of Actuaries.

Leibfritz, W. (2003). Retiring later makes sense. Norway: OECD Observer, Economic Policy Reforms.

Lindell, C. (2003). Longevity is Increasing. What about the Retirement Age? Finnish Centre for Pensions. Paper presented at 4th International Research Conference on Social Security, Finland.

Machnes, Y. (2000). Increasing Life Expectancy and Reforms in Pension Plans. Israel: Department of Economics, Bar-Ilan University.

Neill, A. (1977). Life Contingencies. London: William-Heinemann Ltd.

Rappaport, A. M. (2002). Living to 100 and beyond: Implications of longer life spans. Journal Benefits Quarterly, 19(2), 27-35. 